\title{
EXPERIMENTAL STUDY ON THE FLOW CHARACTERISTICS FOR WIND OVER A TWO-DIMENSIONAL UPWIND SLOPE ESCARPMENT
}

\author{
Ben-Jue Tsai \\ Department of Harbor and River Engineering, National Taiwan Ocean University, Keelung, Taiwan, R.O.C. \\ Bao-Shi Shiau \\ Department of Harbor and River Engineering, National Taiwan Ocean University, Keelung, Taiwan, R.O.C., \\ bsshiau@gate.sinica.edu.tw
}

Follow this and additional works at: https://jmstt.ntou.edu.tw/journal

Part of the Engineering Commons

\section{Recommended Citation}

Tsai, Ben-Jue and Shiau, Bao-Shi (2011) "EXPERIMENTAL STUDY ON THE FLOW CHARACTERISTICS FOR WIND OVER A TWO-DIMENSIONAL UPWIND SLOPE ESCARPMENT," Journal of Marine Science and Technology. Vol. 19: Iss. 5, Article 1.

DOI: $10.51400 / 2709-6998.2159$

Available at: https://jmstt.ntou.edu.tw/journal/vol19/iss5/1

This Research Article is brought to you for free and open access by Journal of Marine Science and Technology. It has been accepted for inclusion in Journal of Marine Science and Technology by an authorized editor of Journal of Marine Science and Technology. 


\section{EXPERIMENTAL STUDY ON THE FLOW CHARACTERISTICS FOR WIND OVER A TWO-DIMENSIONAL UPWIND SLOPE ESCARPMENT}

\begin{abstract}
Key words: turbulent boundary layer flow, upwind slope escarpment, speed-up, turbulence intensity, Reynolds stress, wind power spectrum.
\end{abstract}

Ben-Jue Tsai* and Bao-Shi Shiau**

\begin{abstract}
In this present study, wind tunnel experiments were conducted to measure the flow and turbulence characteristics for wind over an upwind slope of $15^{\circ}$ escarpment. The mean wind speed and turbulence statistics, such as turbulence intensity, Reynolds stress, and wind power spectrum are investigated. Results indicate that wind speed-up phenomenon (increase of speed) occurred significantly around the tip of the upwind slope. The turbulence intensity decreases gradually as the wind flows from the toe of upwind slope to the tip of upwind slope. The wind power spectra for several sites along the upwind slope and top surface of escarpment at lower height display a $-5 / 3$ slope in the inertia-subrange, as predicted by the Kolmogorov's hypothesis. And the dominant spectrum peak was not found as wind over the upwind slope and top surface of escarpment.
\end{abstract}

\section{INTRODUCTION}

For wind engineering problems of wind flow modeling and the estimation of pollution dispersion or wind environment around the buildings or structures that are situated on the exposed hill or escarpment sites, it is necessary to understand the flow and turbulence characteristics for wind past the hill, embankment, or escarpment. In the recent years, there had some typical numerical and experimental studies on this kind of problems. Deave [8], and Utsunomiya et al. [15], for example, they proposed computational and measurement studies

Paper submitted 12/09/09; revised 03/08/10; accepted 04/04/10. Author for correspondence: Bao-Shi Shiau (e-mail: bsshiau@gate.sinica.edu.tw).

*Department of Harbor and River Engineering, National Taiwan Ocean University, Keelung, Taiwan, R.O.C.

**Department of Harbor and River Engineering, National Taiwan Ocean University, Keelung, Taiwan, R.O.C. for flow over embankments or hills. Kobayashi [10] used numerical method to study turbulent flow over and in a model forest in a 2-dimensional hill. Miller [12] made guidelines for the calculation of wind speed-ups in complex terrain. Bowen \& Lindley [3], and Carpenter \& Locke [6], they performed the experimental measurement works on wind speed and turbulence characteristics of flow over embankment with slope angle greater than $14.5^{\circ}$ or multiple hills. Cao and Tamura $[4,5]$ studied the roughness blocks effect on the atmospheric boundary layer flow over a two-dimensional low hill withwithout sudden roughness change. Shiau and Hsieh [13] conducted wind tunnel measurement on the flow characteristics for flow over a two-dimensional embankment of trapezoidal shape with slope greater than $15^{\circ}$. Shiau and Hsu [14] measured the Reynolds stress structure and turbulence characteristics of the wind above a two-dimensional trapezoidal shape of hill.

In fact, the wind flow past the upwind slope escarpment is often encountered in the coastal complex terrain. The variations of flow and turbulence characteristics are of interesting and important for some wind or coastal engineering problems. In the review of air flow over complex terrain by Finnigan [9] indicated that the wind flow separation occurred for two-dimensional hill with slope greater than $16^{\circ}$. Therefore in the present study, we conducted the experimental measurements in wind tunnel to investigate the wind flow and turbulence statistics for the turbulent boundary layer flow over a twodimensional upwind slope of $15^{\circ}$ escarpment.

\section{EXPERIMENTAL SET-UP}

The experiments were conducted in the Environmental Wind Tunnel of National Taiwan Ocean University. The wind tunnel has an area contraction ratio of $4: 1$, and the test section is of $2 \mathrm{~m}$ by $1.4 \mathrm{~m}$ and $12.6 \mathrm{~m}$ long. The turbulence intensity in the empty tunnel test section is less than $0.5 \%$ at a mean velocity of $5 \mathrm{~m} / \mathrm{s}$.

An X-type hot-wire incorporating with the TSI IFA-300 constant temperature anemometer was employed to measure the turbulent flow signals. Output of the analog signals for 

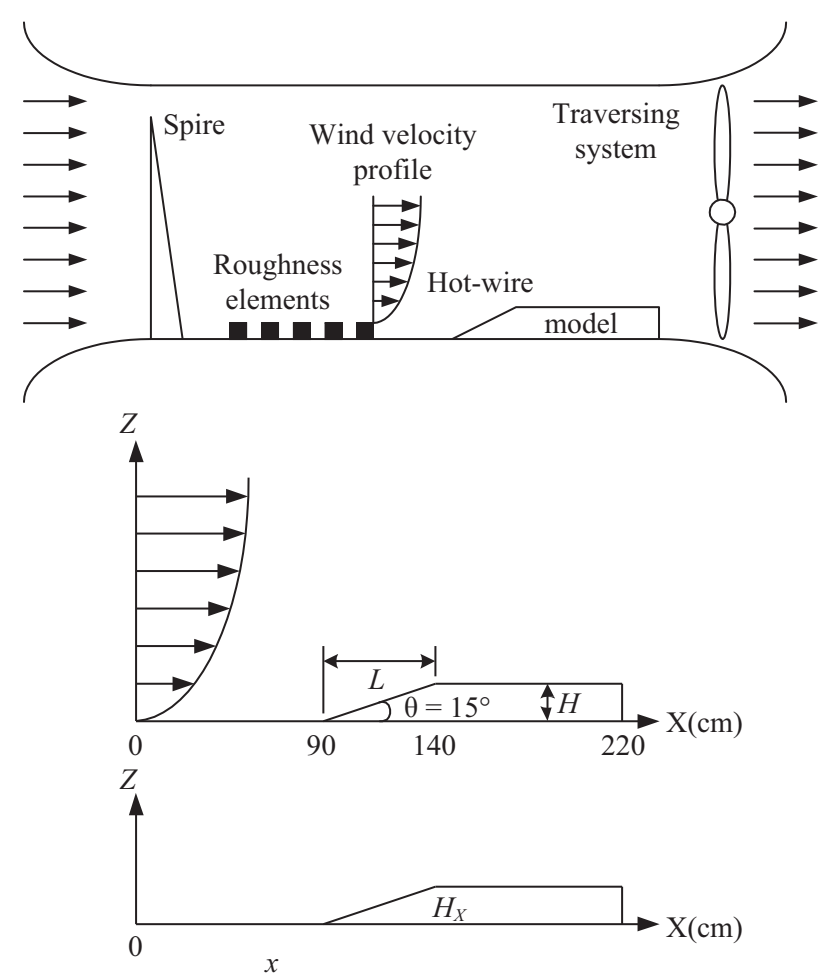

Fig. 1. Schematic diagram of the experimental arrangement and measurement.

turbulent flow was digitized at a rate of $2 \mathrm{kHz}$ each channel through the 12 bit Analog-to-Digital converter. Since none of the analog signals containing significant energy or noise above $1 \mathrm{kHz}$, with the Nyquist criteria, a digitizing rate of $2 \mathrm{kHz}$ was sufficient. The low pass frequency for the analog signals is set as $1 \mathrm{kHz}$ in all runs of the experiments.

A two-dimensional upwind slope of $15^{\circ}$ escarpment model with the height $H=13.4 \mathrm{~cm}$ and upwind slope horizontal length $L=50 \mathrm{~cm}$ was constructed. Four spires are properly arranged crossing the entrance of test section, and roughness elements are deployed succeeding the spires to generate a thick turbulent boundary layer flow. The measurement of coordination origin was set at ground level and $90 \mathrm{~cm}$ before the beginning of escarpment toe. The schematic diagram of experimental arrangement and measurement coordinates were shown in Fig. 1.

To avoid the flow separation (i.e. reversed flow) occurred along the upwind slope surface and top surface of the two-dimensional escarpment, the upwind slope angle of the embankment adopted in the present study was the mild slope with slope angle of $15^{\circ}$. As shown by the Reynolds-number similarity (asymptotic invariance), the flow is approximately independent of the Reynolds number if the Reynolds number is greater than the critical number of $10^{4}$. In the present study of wind tunnel measurement, the Reynolds number $(R e=U L / v$, $U$ is the free stream velocity about $4.0 \mathrm{~m} / \mathrm{s}, L$ is the characteristic length can be represented by the thickness of turbulent boundary layer in wind tunnel about $1.0 \mathrm{~m}, v$ is the kinematic

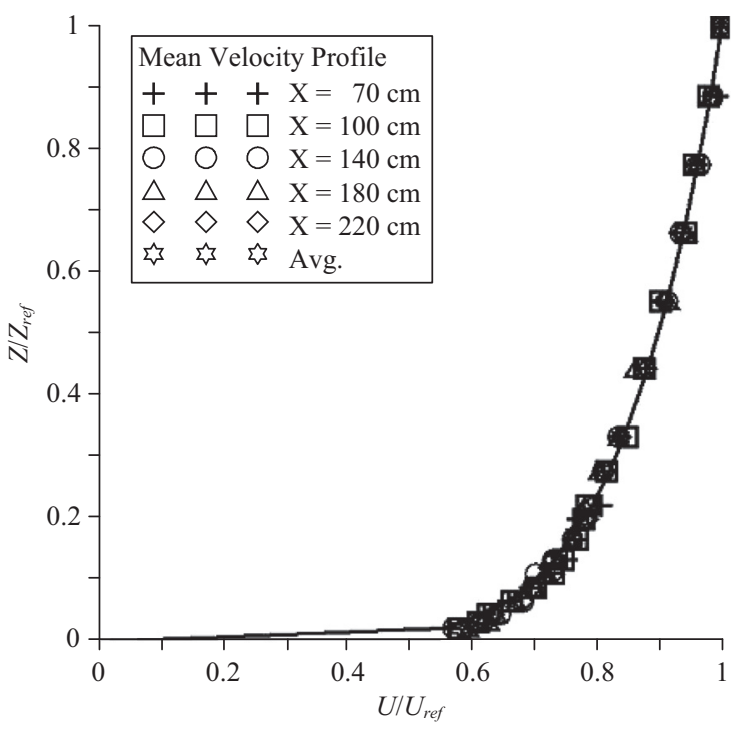

Fig. 2. Mean velocity profiles of approaching flow at various downstream distances without escarpment model.

viscosity of air) is about $2.58 \times 10^{5}$ which is greater than the critical value. So the Reynolds number effect can be neglected in the study.

\section{RESULTS AND DISCUSSION}

\section{Turbulent Boundary Layer Flow as the Approaching Flow}

Four spires of $100 \mathrm{~cm}$ height arranged across the entrance of test section and with roughness elements $(2 \mathrm{~cm} \times 2 \mathrm{~cm} \times 2$ $\mathrm{cm}$ ) deployed succeeding in the test section floor for 8 meters long behind the spires. Such arrangements ensure to generate a thick turbulent boundary layer flow. The rural terrain type of neural atmospheric boundary layer flow was simulated as the approaching flow. The mean velocity profiles measured at different downstream locations without escarpment model are shown in Fig. 2. The turbulent boundary layer thickness is of about $Z_{\text {ref }} \cong 100 \mathrm{~cm}$, and the free stream velocity is of $U_{\text {ref }} \cong 8$ $\mathrm{m} / \mathrm{s}$. The turbulent boundary layer flow profile expressed in power law form as follows:

$$
\frac{U}{U_{r e f}}=\left(\frac{Z}{Z_{r e f}}\right)^{a}
$$

In the present study, the power law with an exponent $a=$ 0.155 , was used as the approaching flow which passed over the upwind slope escarpment model. This value lies in the range of 0.143 to 0.167 as proposed by Counihan [7] for the rural terrain type of neural atmospheric boundary layer flow.

The longitudinal turbulence intensity profiles of approaching flow at different downstream locations without escarpment model are shown in Fig. 3. The longitudinal turbulence intensity $\mathrm{I}(\mathrm{u})$ is defined as the ratio of root mean square of wind 


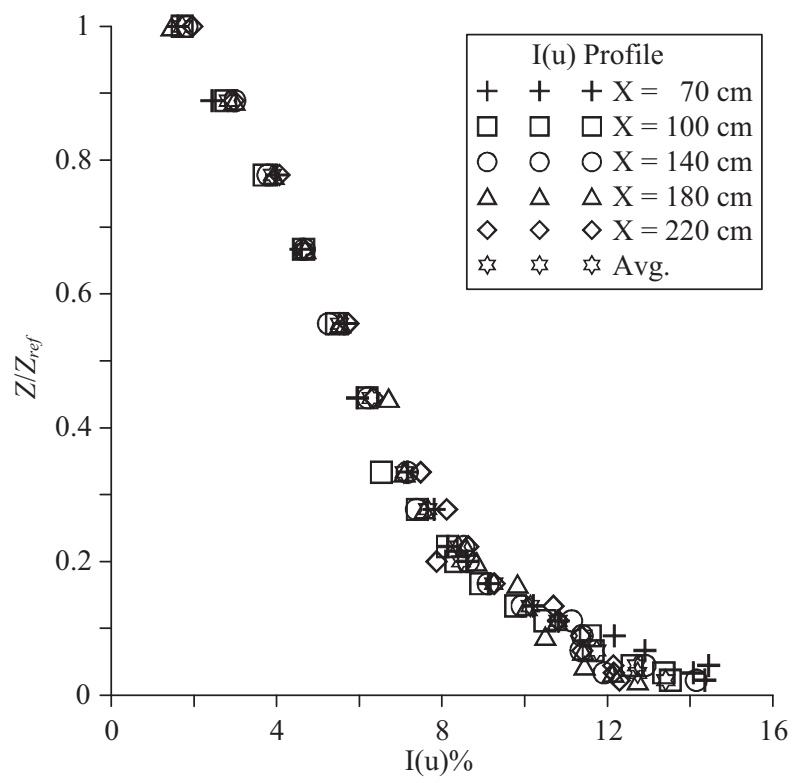

Fig. 3. Longitudinal turbulence intensity profiles of approaching flow at various downstream distances without escarpment model.

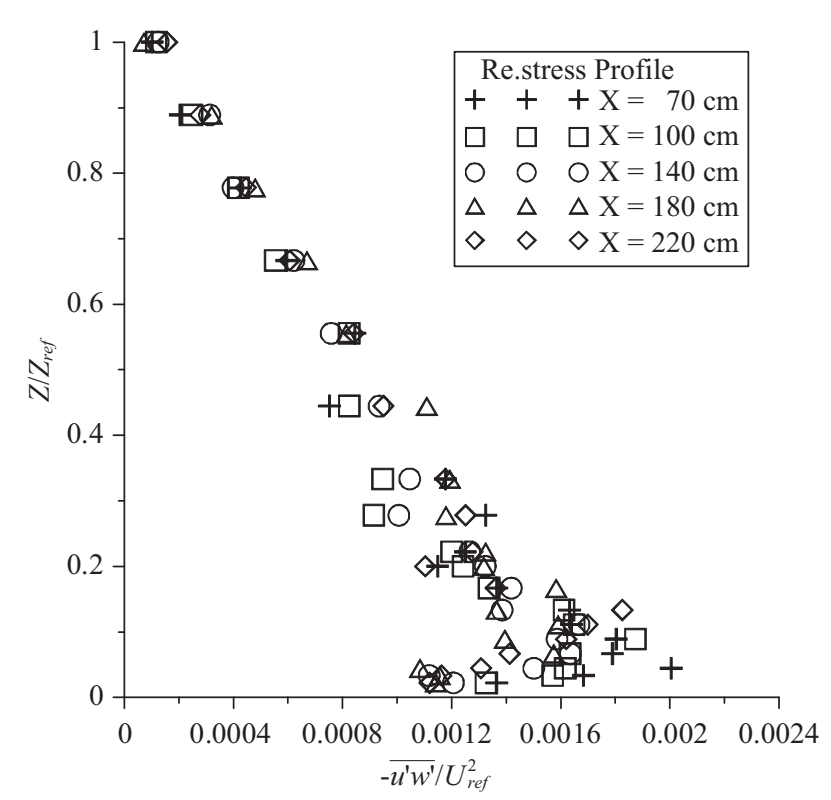

Fig. 4. Reynolds stress profiles of approaching flow at various downstream distances without escarpment model.

velocity fluctuation and the local mean wind speed. The turbulence intensity close to the ground is approximately $15 \%$. Counihan [7] had found that the longitudinal turbulence intensity near the wall in the rural areas fell in the range of $10 \%$ to $20 \%$. Fig. 4 shows the Reynolds stress profiles of approaching flow at different downwind locations. The Reynolds stress, $-\overline{u^{\prime} w^{1}} / U_{r e f}^{2}$ is the mean correlation of longitudinal and vertical wind velocity fluctuations scaled by the square of free stream velocity.

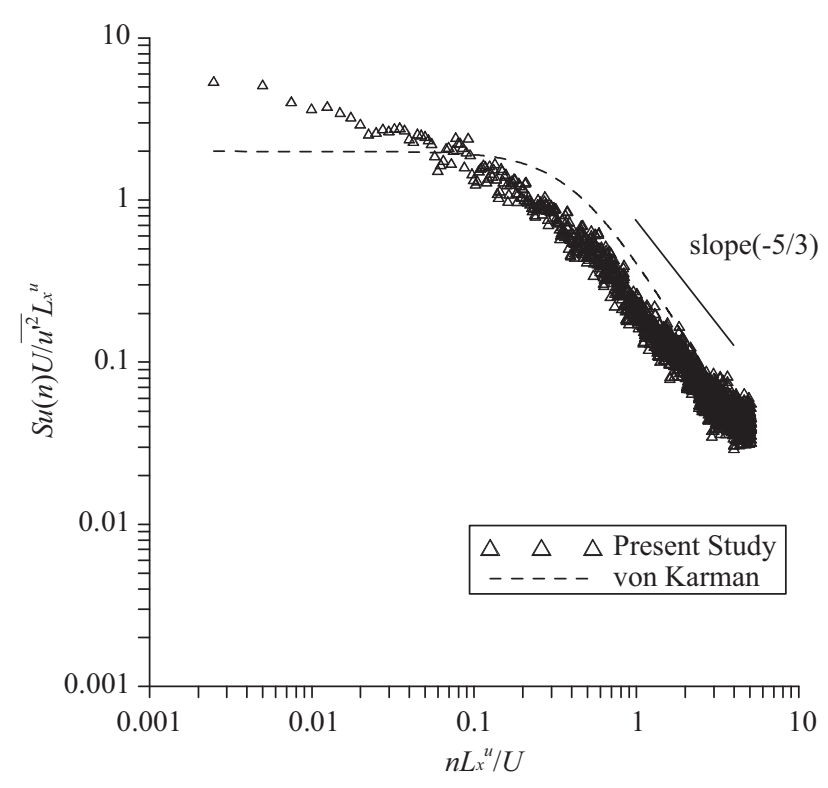

Fig. 5. Turbulent velocity power spectrum of approaching flow; $Z / Z_{\text {ref }}=$ 0.4.

The turbulent velocity power spectrum of approaching flow measured at $Z / Z_{\text {ref }}=0.4$ is shown in Fig. 5. Maeda and Makino [11] rewrote the Von-Karman type power spectrum equation (see Eq. (1)), and such Von-Karman type power spectrum equation is also plotted and shown in the Fig. 5 for comparison.

$$
S_{u}(n)=\frac{2 \overline{u^{\prime 2}} L_{x}{ }^{u}}{U\left[1+\left(\frac{2 c n L_{x}^{u}}{U}\right)^{2}\right]^{\frac{5}{6}}}
$$

In the Fig. 5, the spectrum density, $S_{u}(n)$ and frequency, $n$ are normalized, and they are denoted by $U S_{u}(n) / \overline{u^{\prime 2}} L_{x}{ }^{u}$ and $n L_{x}{ }^{u} / U$, respectively. Here $\overline{u^{\prime 2}}$ denotes the mean square of longitudinal velocity fluctuation; $c$ is the coefficient of 4.2065; $L_{x}{ }^{u}$ is the integral length scale of longitudinal velocity in $x$ direction (i.e. streamwise direction); $U$ is the longitudinal mean velocity at the height of $Z$. The integral length scale is obtained by multiplying the integral time scale, $T_{E}$ with the longitudinal mean velocity, $U$. It is found that present result closes to the Von Karman equation, and the inertia-subrange of turbulence spectrum of approaching flow is with slope $-5 / 3$ which is in agreement with the Kolmogrove spectrum law.

\section{Mean Flow and Speed-up for Wind over Upwind Slope Escarpment}

As the turbulent boundary layer flow as approaching flow passed over the two-dimensional upwind slope escarpment, the flow was forced to pass along the upwind slope surface of escarpment. When the wind flow comes through the upwind slope of the escarpment, the wind flow is accelerating. As it 

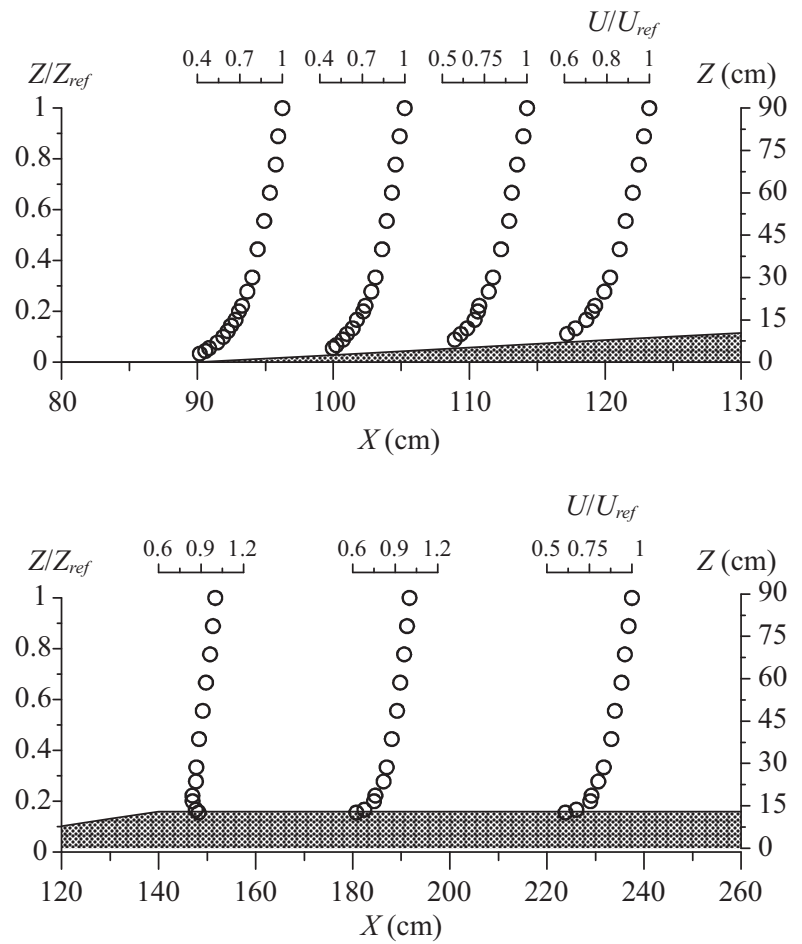

Fig. 6. Mean velocity profiles at various downstream stations for upwind slope of escarpment model.

reaches the top surface of the escarpment, the wind flow decelerates and gradually recovers to the original mean velocity profile of the approaching flow along the downwind distance of top surface of the escarpment. Finnigan [9] indicated that the wind flow separation occurred for two-dimensional hill with slope greater than $16^{\circ}$. To avoid the flow separation (i.e. reversed flow) occurred along the upwind slope surface and top surface of the escarpment, the upwind slope angle of the escarpment adopted in the present study was the mild slope with slope angle of $15^{\circ}$.

The mean velocity profiles at different downstream stations from the toe of upwind slope of escarpment $(x=90 \mathrm{~cm})$ were measured. Fig. 6 shows the mean velocity profiles at different downstream stations $(x=99 \mathrm{~cm}, 108 \mathrm{~cm}, 117 \mathrm{~cm}, 126 \mathrm{~cm}, 140$ $\mathrm{cm}, 180 \mathrm{~cm}$, and $220 \mathrm{~cm}$ ). It is noted from the results of Fig. 6 that as wind flows over the upwind slope of escarpment, the mean velocity profile is changing and increasing gradually along the downstream distance of upwind slope of escarpment The wind velocity profiles shown in Fig. 6 exhibited the flow separation did not occur when wind was past the upwind slope of escarpment. The wind speed is shown to increase dramatically around the tip of upwind slope of escarpment $(x=140$ $\mathrm{cm})$ as comparing with that of the approaching flow. The increase of the mean velocity is the so-called wind speed-up. The wind speed-up phenomenon gradually diminishes and the mean velocity profile recovers to that of the approaching flow in the upstream when the wind flows succeeding along the downstream distance of the escarpment.

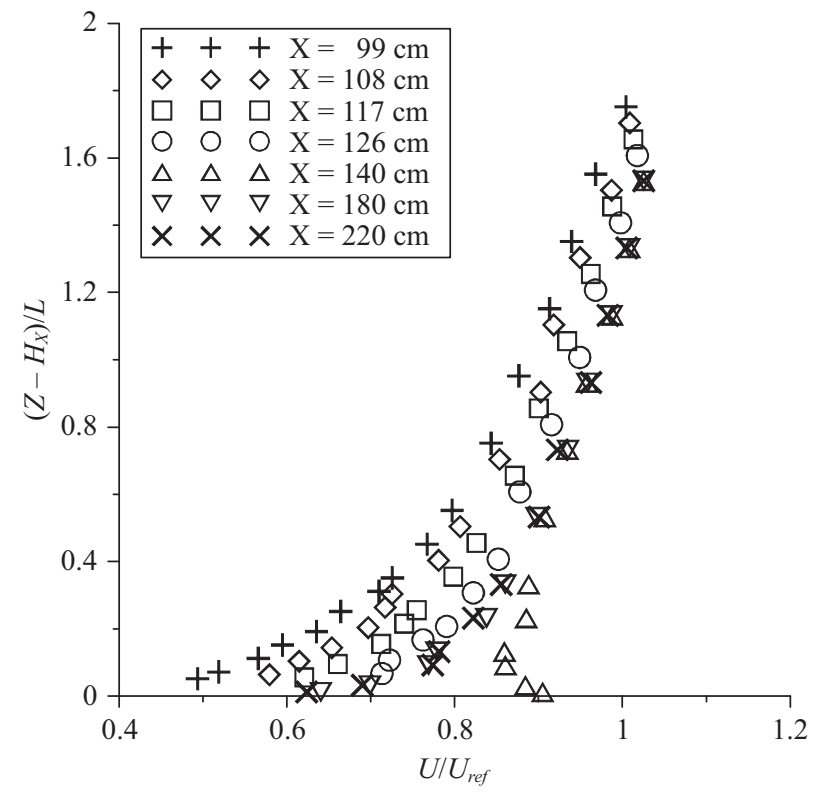

Fig. 7. Mean velocity profiles variations for wind over the upwind slope of escarpment.

For comparing the variations of mean velocity profiles at different downstream stations, we alter the height, $Z$ of the mean velocity profiles shown in Fig. 6 into the relative height, i.e. $Z-H_{x}$. Referring to Fig. $1, Z$ is the height above the ground level; and $H_{x}$ is the height of escarpment at which the downstream distance is $x$. It means the height for each profile measures from the topographical surface of the upwind slope of escarpment. The mean velocity profiles in dimensionless relative height, $\left(Z-H_{x}\right) / L$ ( $L$ : the horizontal length from the toe to the tip of the upwind slope of escarpment model) for different downstream stations are shown in Fig. 7. Results show that the mean velocity increases as the wind over from the toe of the upwind slope of escarpment until it reaches the tip of the slope $(x=140 \mathrm{~cm})$. The increase of the wind velocity is generally called speed-up. The phenomenon of speed-up is caused obviously by the wind flow accelerating from the toe to the tip of upwind slope of escarpment as seen from flow continuity. As the wind reaches the tip of slope of the escarpment $(x=140$ $\mathrm{cm}$ ), the wind flow speed reached the maximum value (see Fig 7). And then the mean velocity decreases when the wind flows along the escarpment in downstream distance (e.g. $x=180 \mathrm{~cm}$ and $220 \mathrm{~cm}$ ).

To investigate the characteristics of wind speed-up phenomenon at different downstream stations of upwind slope of escarpment, we defined a wind speed-up parameter, $A_{z}$

$$
A_{Z}=U\left(Z-H_{x}\right) / U_{s}(Z)
$$

where $U_{s}(Z)$ is the mean velocity at the height $Z$ in the upstream of upwind slope of escarpment (i.e. undisturbed flow by the escarpment). 
Table 1. Parameters for speed-up over hills and escarpments in ASCE 7-02 [1].

\begin{tabular}{|c|c|c|c|c|c|c|}
\hline \multicolumn{7}{|c|}{ Parameters for Speed-Up Over Hills and Escarpments } \\
\hline \multirow{3}{*}{ Hill Shape } & \multirow{2}{*}{\multicolumn{3}{|c|}{$\begin{array}{l}K_{1} /\left(H / L_{h}\right) \\
\text { Exposure }\end{array}$}} & \multirow{3}{*}{$\gamma$} & \multicolumn{2}{|c|}{$\mu$} \\
\hline & & & & & \multirow{2}{*}{ Upwind of Crest } & \multirow{2}{*}{ Downwind of Crest } \\
\hline & $\mathrm{B}$ & $\mathrm{C}$ & $\mathrm{D}$ & & & \\
\hline $\begin{array}{l}\text { 2-dimensional ridges } \\
\text { (or valleys with negative } H \text { in } K_{1} /\left(H / L_{h}\right)\end{array}$ & 1.30 & 1.45 & 1.55 & 3 & 1.5 & 1.5 \\
\hline 2-dimensional escarpments & 0.75 & 0.85 & 0.95 & 2.5 & 1.5 & 4 \\
\hline 3-dimensional axisym. hill & 0.95 & 1.05 & 1.15 & 4 & 1.5 & 1.5 \\
\hline
\end{tabular}

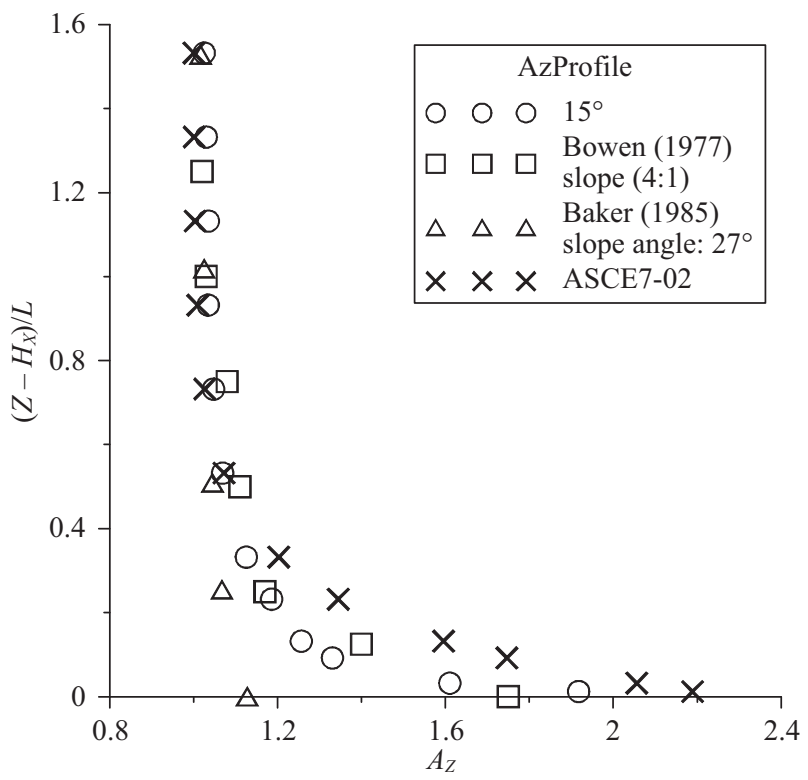

Fig. 8. Wind speed-up parameter, $A_{z}$ profile at the tip of the upwind slope of escarpment $(x=140 \mathrm{~cm}) ; \circ$ : present study.

Fig. 8 presents the $A_{z}$ profiles of present measurements at the tip of the upwind slope of escarpment $(x=140 \mathrm{~cm})$. In Fig. 8 , we also compare with the experimental results of Bowen $\&$ Lindley [5] (slope angle $14.5^{\circ} \mathrm{C}$ of escarpment), and Baker [2] (slope angle $27^{\circ}$ of embankment). It is found that the $A_{z}$ profile of the present measurement is very close to that of the Bowen's result. The Barker's experimental data [2] for $A_{z}$ are shown to be smaller that of the present measurement of slope angles $\left(15^{\circ}\right)$ and Bowen \& Lindley's [3] (slope angle $14.5^{\circ}$ ). The slope angle for Barker's case is $27^{\circ}$, which flow separation may occurre at the tip of embankment. The flow separation reduced the effect of wind speed-up, therefore the parameter, $A_{z}$ becomes smaller.

Furthermore, the velocity profile in the case of an escarpment provided by the ASCE 7-02 [1] was also compared with the present measurement. The speed-up parameter $A_{z}$ used in the present paper corresponds to the topographic facter, $K_{z t}$ appeared in ASCE 7-02 [1],

$$
K_{z t}=\left(1+K_{1} K_{2} K_{3}\right)^{2}
$$

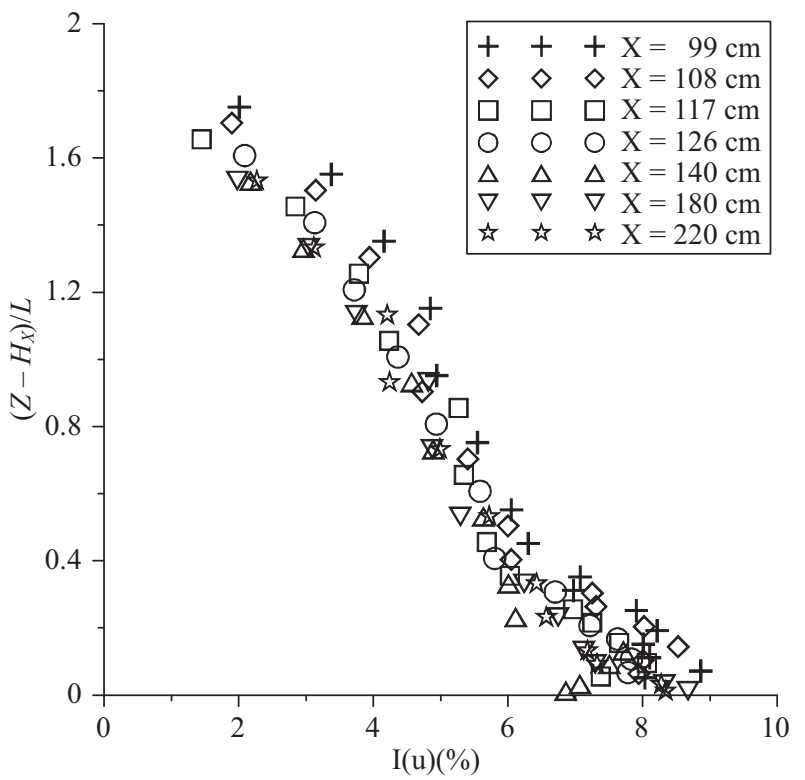

Fig. 9. Longitudinal turbulence intensity profiles at various downstream stations for wind flow over the upwind slope of escarpment.

where $K_{1}$ is determined from the Table 1 . In present study, the hill shape is two-dimensional escarpmant with the category of exposured D. $K_{2}$ is 1.0 at the tip of upwind slope of escarpment. $K_{3}$ is related to the height over the escarpment.

Results of Fig. 8 reveal that the values of $A_{z}$ close to ground as proposed by ASCE 7-02 [1] are shown to be larger than that of the present experimental measurements and Bowen \& Lindley's [3]. It means that the wind velocity proposed by ASCE 7-02 [1] is more conservative. This is reasonable, because the design values shown in code sholud be generally larger for the purpose of safety.

\section{Wind Turbulence Statistics}

The wind turbulence statistics, such as longitudinal turbulence intensity, and Reynolds stress are measured and investigated. Fig. 9 shows the longitudinal turbulence intensity profiles at various downstream stations for wind over the upwind slope of escarpment. The turbulence intensity profile decreases gradually as the wind flows from the toe of upwind slope $x=99 \mathrm{~cm}$ to the tip of upwind slope $x=140 \mathrm{~cm}$. The turbulence intensity profile for height $\left(Z-H_{x}\right) / L<0.4$ is shown 


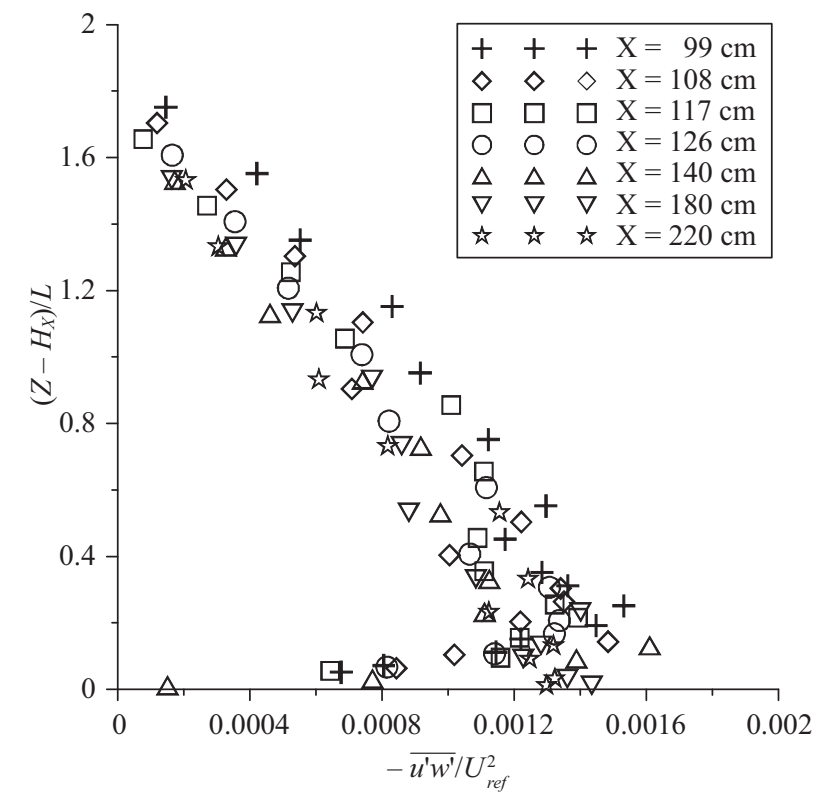

Fig. 10. Reynolds stress profiles at various downstream stations for wind flow over the upwind slope of escarpment.

to be smaller at the location around the tip of upwind slope.

Since the turbulence intensity, $\mathrm{I}(\mathrm{u})$ is defined as the ratio of root mean square of wind velocity fluctuation and the local mean wind speed. And the local mean wind speed increased dramatically due to the significant wind speed-up phenomenon for height $\left(Z-H_{x}\right) / L<0.4$. Therefore the turbulence intensity becomes smaller. Bowen and Lindley [3] investigated the wind speed and turbulence characteristics close to the ground over various escarpment shapes, they also obtained similar tendency for turbulence intensity.

Fig. 10 shows the Reynolds stress profiles at various downstream stations for wind over the upwind slope of escarpment. Results reveal that the Reynolds stress at the heights smaller $\left(Z-H_{x}\right) / L<0.4$ are shown to be minimum at the location around the tip of upwind slope of escarpment $(x=140 \mathrm{~cm})$.

\section{Wind Power Spectrum}

Wind spectra analysis was carried on the longitudinal wind velocity fluctuations to assist inspection on the wind turbulence characteristics along the upwind slope and top surface of escarpment. The non-dimensional wind power spectra for several sites along the upwind slope and top surface of escarpmentat from $x=99 \mathrm{~cm}$ to $x=220 \mathrm{~cm}$ at the same relative height $\left(Z-H_{x}\right) / L=0.2$ are shown in Fig. 11. Result display the wind power spectra distributions with a $-5 / 3$ slope in the inertia-subrange, as predicted by the Kolmogorov's hypothesis. The very dominant spectrum peak which representing the vortex-shedding frequency usually occurred for bluff body or flow separation was not found as wind over the upwind slope and top surface escarpment of present study. This demonstrates the flow separation do not happen as wind over the upwind slope $15^{\circ}$ escarpment. It is also shown in Fig. 11 that

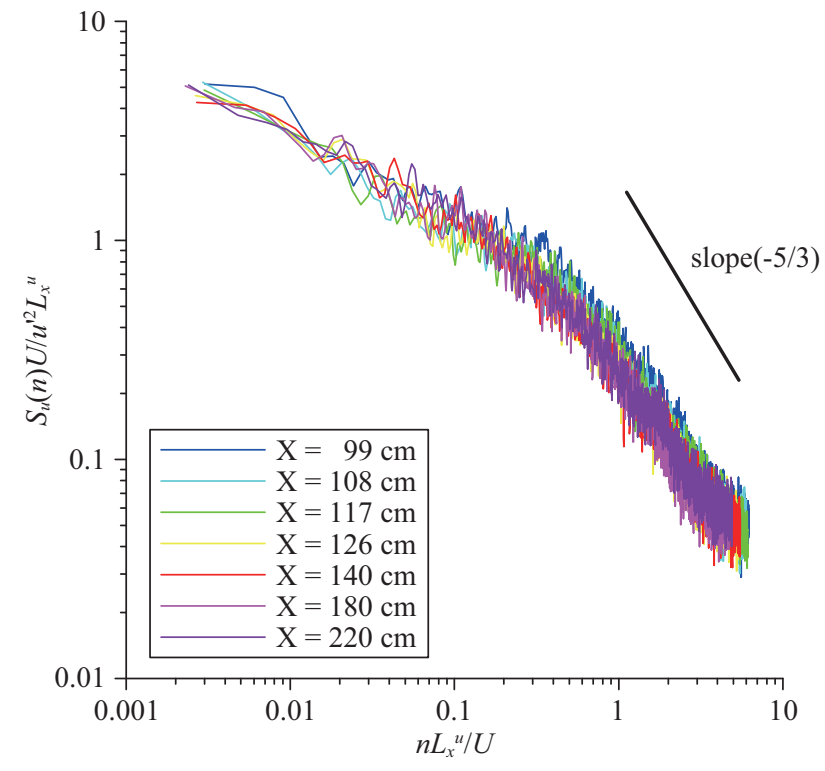

Fig. 11. Non-dimensional turbulent wind power spectra at $\left(Z-H_{x}\right) / L=$ 0.2 with different downstream stations of escarpment surface.

the power density in the lower frequency region decreases as wind over the upwind slope of escarpment (from $x=99 \mathrm{~cm}$ to $x=140 \mathrm{~cm})$.

\section{CONCLUSION}

Experimental measurement study on the flow and turbulence characteristics for wind over a two-dimensional upwind slope of $15^{\circ}$ escarpment were performed in wind tunnel. Results are summarized as:

(1) The mean velocity profiles along the upwind slope and escarpment surfaces show that wind speed-up phenomenon (increase of speed) occurs significantly around the tip of the upwind slope. And the mean velocity profile recovers gradually along the downstream distance from the tip of the upwind slope.

(2) Analysis of wind turbulence characteristics show that the turbulence intensity decreases gradually as the wind flows from the toe of upwind slope to the tip of upwind slope. And the turbulence intensity at the lower height is small at the location around the tip of upwind slope.

(3) The wind power spectra for several sites along the upwind slope and top surface of escarpment at lower height display a $-5 / 3$ slope in the inertia-subrange, as predicted by the Kolmogorov's hypothesis. And the dominant spectrum peak was not found as wind over the upwind slope and top surface of escarpment.

\section{REFERENCES}

1. American Society of Civil Engineering, Minimum Design Loads for Buildings and Other Structures, ANSI/ ASCE 7-02 (2002). 
2. Baker, C. J., "The determination of topographical exposure factors for railway embankments," Journal of Wind Engineering and Industrial Aerodynamics, Vol. 21, pp. 89-99 (1985).

3. Bowen, A. J. and Lindley, D., "A wind tunnel investigation of the wind speed and turbulence characteristics close to the ground over various escarpment shapes,” Boundary Layer Meteorology, Vol. 12, pp. 259-271 (1977).

4. Cao, S. and Tamura, T., "Experimental study on roughness effects on turbulent boundary layer flow over a two-dimensional steep hill," Journal of Wind Engineering and Industrial Aerodynamics, Vol. 94, pp. 1-19 (2006)

5. Cao, S. and Tamura, T., "Effects of roughness blocks on atmospheric boundary layer flow over a two-dimensional low hill with/without Sudden Roughness Change," Journal of Wind Engineering and Industrial Aerodynamics, Vol. 95, pp. 679-695 (2007).

6. Carpenter, P. and Locke, N., "Investigation of wind speeds over multiple two-dimensional hills," Journal of Wind Engineering and Industrial Aerodynamics, Vol. 83, pp. 109-120 (1999).

7. Counihan, J., "Adiabatic atmospheric boundary layers: a review and analysis of data from the period 1880-1972," Atmospheric Environment, Vol. 3, pp. 871-905 (1975).

8. Deave, D. M., "Computations of wind flow over two-dimensional hills and embankments," Journal of Wind Engineering and Industrial Aerodynamics, Vol. 6, pp. 89-111 (1980).
9. Finnigan, J. J., “Air flow over complex terrain,” in: Steffen, W. L. and Denmead, O. T. (Eds.), Flow and Transport in the Natural Environment, Springer, Heidelberg, pp. 183-229 (1988).

10. Kobayashi, M. H., "Numerical study of the turbulent flow over and in a model forest on a 2D hill," Journal of Wind Engineering and Industrial Aerodynamics, Vol. 53, pp. 357-374 (1994).

11. Maeda, J. and Makino, M., "Power spectra of longitudinal and lateral wind speed near the ground in strong winds," Journal of Wind Engineering and Industrial Aerodynamics, Vol. 28, pp. 31-40 (1988).

12. Miller, C. A., "Guidelines for the calculation of wind speed-ups in complex terrain," Journal of Wind Engineering and Industrial Aerodynamics, Vol. 74-76, pp. 189-197 (1998).

13. Shiau, B. S. and Hsieh, C. T., "Wind flow characteristics and Reynolds stress structure around the two-dimensional embankment of trapezoidal shape with different slope gradients," Journal of Wind Engineering and Industrial Aerodynamics, Vol. 90, pp. 1645-1656 (2002).

14. Shiau, B. S. and Hsu, S. C., "Measurement of the Reynolds stress structure and turbulence characteristics of the wind above a two-dimensional trapezoidal shape of hill," Journal of Wind Engineering and Industrial Aerodynamics, Vol. 91, No. 10, pp. 1237-1251 (2003).

15. Utsunomiya, H., Nagao, F., and Noda, M., "Effects of roughness change on wind properties around two-dimensional hills," in: Larsen, A., Larose, G. L., and Livesey, F. M. (Eds.), Wind Engineering into the 21st Century, Balkema, Rotterdam, pp. 369-376 (1999). 